\title{
REFLEXÕES DA PRÁTICA PEDAGÓGICA VOLTADA A CRIAÇÃO MUSICAL
}

\author{
REFLECTIONS OF PRACTICE EDUCATIONAL TO THE MUSICAL CREATION \\ REFLEXIONES DE LA PRÁCTICA PEDAGÓGICA PARA LA CREACIÓN MUSICAL
}

\author{
CRUZ, Fernando Vieira da \\ CRUZ, Dayana Aparecida Marques de Oliveira²
}

\begin{abstract}
RESUMO
As metodologias em educação musical difundidas a partir do século XX são amplamente discutidas levando em conta a execução, a escuta ativa e a criatividade. Neste contexto faz se necessário a elaboração de atividades que considerem estas práticas como elementos essenciais na experiência musical vivenciada em sala de aula. Destaca-se o desenvolvimento de atividades pedagógicas voltadas à criação musical, atividades estas realizadas no Projeto Guri a partir do ano de 2011. Tais atividades podem ser consideradas como indicativos de uma prática pedagógica contextualizada com as propostas metodológicas aqui apresentadas.
\end{abstract}

Palavras-chave: Música. Educação Musical. Prática Pedagógica. Criação Musical. Projeto Guri.

\section{ABSTRACT}

The methodologies in music education broadcasts from the twentieth century are widely discussed taking into account the instrument practice, active listening and creativity. In this context it is necessary the development of activities that consider these practices as essential elements in the music lived in the classroom. In this work the focus is the development of musical creation pedagogical activities, the activities that are carried out in "Projeto Guri" in Brazil from the year 2011. Such activities can be considered as indicative.

Keywords: Music Education. Pedagogical Practice. Musical creation. Projeto Guri.

\section{RESUMEN}

Las metodologías en educación musical transmitidas a partir del siglo XX tienen sido discutidas ampliamente teniendo en cuenta la práctica instrumental, la escucha activa y la creatividad. En este contexto, es necesario el desarrollo de actividades que consideran estas prácticas como elementos esenciales en la música vivida por los estudiantes en el aula. Cabe destacar en el desarrollo de actividades pedagógicas de creación musical, las actividades que se llevan a cabo en "Projeto Guri" en Brasil a partir del año 2011. Estas actividades pueden ser consideradas como indicativos de una práctica pedagógica contextualizada con las propuestas metodológicas aquí a presentadas

Palabras clave: Música. Educación Musical. Práctica Pedagógica. La creación musical. Projeto Guri.

\footnotetext{
1 Universidade Estadual de Campinas - UNICAMP - Campinas - São Paulo - Brasil.

2 Universidade Estadual Paulista - UNESP - Ourinhos - São Paulo - Brasil.
} 


\section{INTRODUÇÃO}

No período atual, o improviso deve ser utilizado na educação infantil como uma maneira de possibilitar à criança a resolução de situações-problema (DEMO, 2003), bem como flexibilidade diante de situações inesperadas auxiliando-a no desenvolvimento do raciocínio e da sociabilidade.

O uso do improviso como ferramenta didática se apoia em atividades de criação musical inseridas na discussão acerca da educação musical do século XX. Segundo Fonterrada (2008), a educação musical do século XX traz uma nova reflexão a respeito da formação musical oferecida em sala de aula cuja principal diferença em relação à formação musical do século XIX é a ausência da valorização isolada do virtuosismo na prática instrumental que foi substituída pela priorização da criatividade musical.

Segundo Swanwick (2003) existem três atividades pedagógicas que estão diretamente ligadas à música e, portanto colocadas como atividades principais. Sãos essas atividades as de execução, apreciação e composição, esta última ligada ao desenvolvimento da criatividade.

Serafine (1988) também aborda essa questão definindo composição como atos deliberados de combinar sons, apreciação como organização ativa e elaboração da escuta musical, e por fim a performance como uma atividade hibrida que envolve a composição e a apreciação.

A música de vanguarda acompanhou as transformações ocorridas na prática pedagógica em música no século $X X$ e aponta um interesse pelo som como matéria prima da música, estando ligada a manipulação do som (FONTERRADA, 2008). Ligado a esta ideia Sloboda (1997) faz uma associação metafórica entre a música e a linguagem, demonstrando que esta associação é válida logo em princípio pelo principal meio de propagação tanto da música quanto da linguagem, que é o som.

Swanwick (2003) ressalta a necessidade de se considerar o discurso musical do aluno, sendo que a própria música deve ser considerada como um discurso, e a fluidez deve estar presente durante todo o processo de aprendizagem. Alinhado a esta ideia Serafine (1988) discute a importância da experiência musical significativa no processo de cognição musical uma vez que a música é um fenômeno cultural resultante de um grupo de pessoas que compartilham compreensões comuns acerca de sua composição, apreciação e apresentação. John Sloboda (1997) vê a música como uma interpretação subjetiva resultante do contexto de quem a cria.

Tendo em vista esses apontamentos iniciais, o artigo discute o improviso como possibilidade da criação musical, necessária para o desenvolvimento da criatividade através da resolução de tarefas cotidianas na sala de aula. A ativa participação dos alunos no processo de aprendizagem fica sempre em evidência, o que nos leva a pensar uma prática pedagógica além de participativa, contextualizada e significativa a partir de experiências desenvolvidas no Projeto Guri durante o ano de $2011 \mathrm{em}$ polos da regional de Presidente Prudente/SP. 


\section{A EDUCAÇÃO MUSICAL NO SÉCULO XX}

No início do século XX surge uma nova visão sobre metodologia em educação musical, e junto dessa visão, os chamados métodos ativos (FONTERRADA, 2008), são chamados assim pela característica da ativa participação dos alunos no processo de aprendizagem. Os métodos ativos em educação musical são propostas ou abordagens pedagógicas que surgiram no início do século XX. Na realidade nem todos eles são considerados métodos, porém como dito, são propostas e abordagens pedagógicas em educação musical (FONTERRADA, 2008).

Fonterrada divide os autores dos métodos ativos em dois grupos, um grupo é chamado de primeira geração e surgiu no início do século XX, principalmente representado pelos seguintes autores: Émile-Jaques Dalcroze, Edgar Willems, Zoltán Kodály, Carl Orff e Shinichi Suzuki. Segundo a autora, a característica mais importante e comum entre todos os autores da primeira geração de métodos ativos aqui citados, é o afastamento de procedimentos técnicos ou teóricos, preferindo que o contato com a música seja como uma experiência de vida, ou seja, valorizando mais a vivência musical.

Nas décadas de 1950 e 1960 surge a segunda geração de educadores musicais na Europa e América do Norte, entre os mais importantes estão: Keith Swanwick, John Sloboda, George Self, John Paynter, Boris Porema e Murray Schafer. A principal diferença entre a primeira e a segunda geração está nas tendências de produção musical seguidas pelos autores da segunda geração cuja ênfase no som como matéria prima da música é maior.

Existe um tripé de práticas pedagógicas que sustenta a educação musical dos métodos ativos, são as atividades de envolvimento direto com a música e referem se a execução, apreciação e criação.

A execução musical seja instrumental ou vocal deve ser com técnica adequada considerando os padrões de afinação, articulação, rítmica, etc. É importante ressaltar que nessa concepção o desenvolvimento técnico de execução instrumental não é o único foco. Cabe notar que, de acordo com Swanwick (2003), as atividades de técnica têm um caráter teórico, e podem estar relacionadas a atividades não vinculadas a execução instrumental, tais como: grafia musical, leitura, manuseio de montagem e desmontagem do instrumento e teoria musical.

A apreciação se refere à chamada escuta ativa da música e percepção da música como um todo. Para Swanwick (2003) o processo de transformação metafórica acontece em três níveis: I as notas são ouvidas como melodias, chamado de "gestos musicais", II as melodias assumem vida própria através de relações internas "expressão transforma-se em forma" e III Melodias relacionam-se com conhecimentos prévios "formas transformam - se em valor".

A criação se dispõe a desenvolver o senso criativo dos alunos. Relaciona-se ao fazer musical vinculado à criatividade, ou seja, além de se decifrar um código musical escrito e interpretá-lo executando uma peça, é preciso criar improvisando, arranjando ou compondo para que o fazer musical seja completo. As atividades de criação musical abordadas em sala de aula devem ir além do conceito tradicional de se estudar o improviso através de escalas e acordes apenas quando os alunos já 
estiverem em um avançado nível técnico de execução. A criação musical deve ser abordada desde o início do processo de aprendizagem, com o professor criando situações em que os alunos se vejam não só na condição de explorar a criatividade, mas na necessidade de improvisar para a resolução de situações-problema (DEMO, 2003).

A partir da leitura de Swanwick (2003), entendemos que as atividades de criação devem estimular a criatividade dos alunos desde a primeira aula, de acordo com o desenvolvimento da pratica instrumental. Aqui devemos preservar a fluência contínua e considerar o discurso musical de cada aluno que traz consigo suas influências musicais, oriundas de espaços formais ou informais de aprendizagem musical.

A prática coletiva, que é outra característica fundamental na educação musical, ampliará o leque de experiências dos alunos, criando paradigmas que embasarão novos fenômenos culturais coletivos entre eles, passando a partilhar de novas compreensões musicais a respeito do que se verifica em Serafine (1988).

Estas novas compreensões trazidas por Serafine em sua vez criarão um novo contexto entre os alunos que resultará em novas interpretações subjetivas, interpretação presente em Sloboda (1997).

\section{O MODELO TECLA}

Para elucidar um pouco mais a respeito da educação musical do século $X X$, abordamos aqui o modelo pedagógico de Keith Swanwick intitulado de modelo CLASP (Composition, Literature Studies, Audition, Skill aquisition, Performace) que foi traduzido para a língua portuguesa como modelo TECLA: técnica, execução, composição e arranjo, literatura e apreciação. Segundo o modelo estes são cinco parâmetros de experiências musicais necessárias para o fazer musical, que referem - se a cinco tipos de atividades.

Os elementos são os mesmos que um planejamento de educação musical deve contemplar. Não existe a necessidade de todos os elementos serem abordados em todas as aulas, porém o planejamento de um período regular como de um semestre, por exemplo, deve contemplar os cinco parâmetros.

Swanwick (2003) aponta que apenas três dos cinco parâmetros de experiências musicais são experiências musicais diretas, a saber: composição, execução e apreciação; as outras duas - técnica e literatura - são atividades que servirão apenas de apoio para as três primeiras relacionadas.

Uma vez que as atividades musicais diretas referem - se ao tripé de atividades pedagógicas que sustentam a educação musical, e já foram abordadas neste trabalho, detalharemos agora as atividades secundárias de Swanwick.

As atividades de técnica não se referem apenas a técnica de execução instrumental, mas aos conhecimentos que servirão de base para as outras atividades, dentre elas citamos a grafia musical, a 
manipulação dos instrumentos musicais - montagem, desmontagem e higienização -, postura para tocar o instrumento e embocadura ${ }^{3}$ no caso dos instrumentos de sopro.

Já as atividades de literatura referem-se a atividades que desenvolvam o conhecimento histórico a respeito das músicas e autores que serão trabalhados nas atividades principais. Elas podem ser desenvolvidas através de pesquisas feitas pelos próprios alunos além de aulas expositivas apoiadas por textos, livros, figuras e etc. Contudo, para Swanwick (2003), essas atividades são de importância secundária, e não podem tomar grande parte das aulas, que devem ser baseadas principalmente em atividades de execução musical.

Para Swanwick (2003) as atividades de criação têm o papel inicial de estimular a criatividade dos alunos, independentemente do grau de seu conhecimento técnico em música, ou da sua capacidade mais ou menos desenvolvida em manipular ou executar um instrumento musical.

Dessa maneira os alunos são estimulados a criar música em todas as fases de seu desenvolvimento musical, inicialmente executando e utilizando duas ou três notas musicais para posteriormente, no mais alto nível de conhecimento musical, se utilizando de complexas estruturas e escalas.

Se por um lado não se pode atribuir um limite para desenvolver a criatividade musical, Swanwick (2003) parece ter transposto as barreiras de quando começar a desenvolver essa criatividade, já que o estudo de improvisação sempre foi reservado a músicos com elevado nível técnico musical - de execução do instrumento e de profundo conhecimento teórico e de harmonia . Swanwick passa a construir a ideia de que a criatividade do aluno deve ser estimulada desde o inicio de seu aprendizado em música, sem importar o nível de conhecimentos técnicos e teóricos.

\section{O PROJETO GURI}

No estado de São Paulo, o Projeto Guri adota o modelo pedagógico de Keith Swanwick como fio condutor de todos os cursos que oferece em seus mais de 300 polos. O Projeto é atualmente o maior programa sociocultural brasileiro, e atende a mais de 51 mil alunos, surgiu em 1995 e oferece a seus alunos no período de contra turno escolar vários cursos musicais (iniciação e teoria musical, coral e instrumentos de cordas, madeiras, sopro e percussão).

O projeto sempre atuou com aulas coletivas de música, e no curso de madeiras, por exemplo, em cada turma são oferecidas duas vagas para flauta, duas vagas para clarineta, uma para saxofone alto e uma para saxofone tenor, formando assim turmas mistas com diferentes instrumentos, a única excessão são os polos regionais criados em 2009, que são apenas 12 pólos em cidades pré determinadas com uma administração regional que serve de apoio a sede situada na capital. Nos pólos regionais cada curso é ministrado separadamente, mesmo sendo em aulas coletivas, por exermplo, no

\footnotetext{
${ }^{3}$ Maneira correta de posicionar os instrumentos de sopro na boca. 
curso de saxofone são oferecidas oito vagas em cada turma sem a presença de flautas e clarinetas na mesma classe.

Cada curso, em todos os pólos pode chegar a atender três turmas por turno, e geralmente essas turmas são separadas por nível de conhecimento musical, nesse caso a primeira turma, chamada de turma $\mathrm{A}$, atende a alunos iniciantes, ingressantes no projeto, a Turma B atende a alunos que já freqüentam o projeto geralmente a mais de um semestre, sendo classificada como de nível intermediário, a turma $C$ é a turma de alunos que freqüentam o projeto ha mais tempo e, portanto é classificada como a turma avançada.

Todos os alunos têm a possibilidade de freqüentar o curso de um instrumento musical e o curso de canto coral, no caso de um pólo completo. Contudo, somente os alunos da turma $\mathrm{C}$ de instrumentos participam tanto das aulas coletivas como da prática de conjunto.

A partir de minha experiência na atuação junto no projeto, percebemos que este têm oferecido várias capacitações aos educadores com base no modelo de Swanwick, realizando inclusive alguns eventos com a presença do próprio autor.

Com base nesta realidade abordamos as atividades de criação com situações em que os alunos possam exercitar a resolução de questões musicais de maneira análoga a solução de questões referentes a tarefas comuns do dia a dia: improvisando. Especificamente na área de sopro, percebemos a possibilidade dessas abordagens espontâneas inclusive pelos métodos utilizados em sala de aula, dentre os quais podemos citar o método "Da Capo" e o "Da Capo Criatividade", ambos desenvolvidos pelo professor Joel Barbosa (1998), vice diretor do curso de licenciatura em música da UFBA - Universidade Federal da Bahia, esses dois métodos adotados pelo Projeto Guri são baseados no modelo pedagógico de Keith Swanwick.

O método "Da capo" é voltado a prática coletiva de música para instrumentos de sopro e percussão, com base no modelo pedagógico de Swanwick é também direcionado a alunos iniciantes nesses instrumentos. Na maior parte de seus exercícios se propõe a desenvolver a prática coletiva de instrumentos de sopro e percussão através de cantigas de rodas e músicas folclóricas brasileiras. Já o método "Da Capo Criatividade" foi desenvolvido para atender especificamente as atividades de criação, baseado no modelo pedagógico de Keith Swanwick.

\section{ATIVIDADES DE CRIAÇÃO}

As atividades em questão foram aplicadas em cinco turmas iniciantes do projeto guri da regional de Presidente Prudente - SP no curso de instrumentos de madeiras (saxofone, clarinete e flauta transversal), o período de aplicação das atividades compreendeu o primeiro e o segundo semestre letivo do ano de 2011. A faixa etária dos alunos era entre oito e dezoito anos, as turmas foram separadas por nível de conhecimento musical, o que implica em trabalhar com turmas de faixa etária diferentes. 
Descrevemos a seguir três atividades de criatividade aplicadas junto a alunos de nível iniciante, além de seus resultados e influências no comportamento dos alunos dentro da sala de aula.

Além da explanação de três atividades, apresentamos uma abordagem condizente com o objetivo de estímulo à criatividade e conforme as referências teóricas apresentadas em tópicos anteriores.

O que este trabalho propõe agora é que as atividades de estímulo à criatividade dos alunos sejam abordadas de maneira inesperada, ou seja, também sendo apresentadas de forma improvisada, criando um ambiente propício aos alunos se verem obrigados a improvisar na resolução situaçõesproblema (DEMO, 2003).

É importante ressaltar que o desenvolvimento dessas atividades é coerente com a proposta de que a experiência na sala de aula seja musicalmente significativa para os alunos quanto ao estimulo da criatividade, tendo como base as contribuições de Serafine (1988).

Essas atividades de estímulo inicial à criatividade dos alunos, além de serem totalmente aplicáveis a turmas iniciantes, podem estar entre as primeiras atividades e fazer parte em alguns casos do primeiro contato dos alunos com o educador em sala de aula. A primeira atividade de estímulo à criatividade desenvolvida nas turmas foi denominada "escala improvisada". Por ser uma atividade relacionada a um conteúdo musical básico, pôde ser desenvolvida no primeiro contato do educador com os alunos da turma.

Atividade: Escala Improvisada: essa atividade propôs que o aluno memorizasse a sequência natural das notas musicais: do, re, mi, fá, sol, la e si, sendo que após a nota si a sequencia de notas recomeça. $\mathrm{Na}$ ordem em que os alunos foram entrando na sala de aula, o educador aponta ao primeiro da fila e lhe diz o nome de uma nota musical, e em sequencia a ação foi repetida com todos os alunos.

Para que o inicio da atividade fosse mais intuitivo foi usada a nota Do. O educador disse o nome dessa nota estimulando o aluno a lhe responder, isso foi feito por gestos e expressões faciais indicando ao aluno que continuasse. Na maioria dos casos, o aluno acabou respondendo mesmo ainda estando em dúvida quanto a estar certo ou não, porém na maioria das vezes o aluno respondeu com certo receio "Ré".

Quando o aluno não entendia a atividade, o educador passava a vez para outro aluno e retornava a vez a esse aluno em seguida.

Esse momento serviu inclusive ao educador como uma avaliação dos conhecimentos básicos em música na nova turma de alunos. O educador avaliou ainda a prontidão de resposta e raciocínio de cada aluno.

Essa é uma atividade que em sua forma inicial, explicada acima, é mais necessária a alunos de idade entre sete e dez anos. Após essa fase inicial, ou com turmas de alunos de maior idade como entre 11 e 15 anos, por exemplo, a atividade pode assumir formas de variações, como ser abordada a 
escala natural das notas musicais em sequência descendente, ou com intervalos entre as notas, sendo que cada aluno responderá a escala na sequência, porém sempre pulando uma nota - o educador diz "Dó" e o aluno deverá pular anota ré e responder "Mi", e assim sucessivamente. Os intervalos entre as notas também devem variar executando a atividade com o maior intervalo possível entre as notas.

$\mathrm{Na}$ forma sequencial, ou seja, sem intervalos entre as notas, essa atividade chegou a uma evolução de ser executada nos instrumentos musicais, quando o educador e os alunos deixaram de falar os nomes das notas para executá-las nos instrumentos. Mas este estágio de evolução da atividade só foi possível com alunos que frequentam o curso ha mais de três semestres

As explicações verbais dessas atividades foram breves a fim de estimular os alunos a se apoiarem cada vez mais na linguagem musical e cada vez menos em explicações teóricas.

A segunda atividade, "imitação e criação de frases" esteve diretamente voltada a estimular a criatividade musical dos alunos, diferentemente da primeira e da terceira atividades que se relacionaram com mais ênfase á espontaneidade musical. Essa atividade foi aplicada a partir da segunda ou terceira aula de turmas iniciantes. Pois foi aplicada inicialmente enquanto os alunos ainda não estavam tocando com o instrumento todo montado, mas apenas utilizando boquilhas e bocais. Os alunos já eram capazes de emitir sons curtos e longos, fortes e fracos com facilidade, mas a afinação nesse momento ainda era relativa e em fase inicial.

Usando uma boquilha ou bocal, o educador criou frases rítmicas para que os alunos o imitassem em seguida respeitando uma determinada pulsação rítmica. De início não foi exigido a diferenciação de sons fortes e fracos, além de que as frases eram simples e de notas longas apenas, situação em que foi mais fácil para os alunos controlarem a embocadura. Aos poucos as frases ficaram mais complexas e com sons mais curtos, o educador passou a exigir também as dinâmicas, diferenciando os sons fortes e fracos.

A partir do momento em que os alunos já ficaram à vontade com a atividade, cada aluno passou a desempenhar o papel até então feito pelo educador. Cada aluno criou uma frase, enquanto os outros alunos continuaram a imitar essa frase, seguindo uma sequência, todos os alunos tiveram a oportunidade de criar várias frases. Foi exigido dos alunos que criassem frases que ainda não foram usadas na atividade até então.

Seguindo a atividade sem interrupções no momento em que os alunos estavam criando as frases, os mesmos se viram na liberdade de tocar/criar livremente, mas também se sentiram na obrigação de o fazer sem perder o ritmo, o que fez com que a atividade não fosse interrompida. Essa é uma situação que se assemelha a improvisação musical no jazz, e ao tema de improviso citado anteriormente neste trabalho: Foi um momento em que cada aluno pôde criar, e improvisar obedecendo a uma regra pré-determinada (nesse caso o ritmo) enquanto fazia música.

A terceira atividade desenvolvida nas turmas foi denominada "complete a música", essa é uma atividade que exigiu certo conhecimento no instrumento musical, os alunos já tinham capacidade de 
executar pelos menos uma sequência de seis notas, além de um domínio básico de afinação, articulação e respiração. As turmas iniciantes estiveram aptas a participar dessa atividade após pelo menos dezesseis aulas de frequência no curso, considerando duas aulas semanais.

O educador executou com a voz a melodia da música "atirei o pau no gato", porém não cantando a letra da mesma, em determinado momento o educador apontou para um aluno e parando de executar a música instigou o aluno a completar a frase. A execução da melodia se deu por repetição de uma única sílaba neste momento.

Após esta primeira etapa o educador substituiu a letra da música na mesma melodia, por uma letra que exigiu uma resposta específica de cada aluno relacionada à sequência das notas naturais da escala musical.

Inicialmente cada aluno executou sempre a mesma frase, sendo cada aluno em um momento diferente.

A atividade foi descrita sem considerar a transposiçã dos instrumentos usados pelos alunos, isso, apenas para simplificar a explicação da atividade.

Essa atividade trabalhou, sobretudo, a espontaneidade musical do aluno, estimulando com maior ênfase o aluno a resolver rapidamente questões de conhecimento teórico (nesse caso a sequência das notas) enquanto tocava, sendo que a resolução dessas questões resultou na execução espontânea da música.

A ênfase dada às atividades musicais diretas está no tempo dedicado às mesmas, e não na ordem em que foram trabalhadas. A primeira atividade, por exemplo, pode ser interpretada como uma atividade de cunho teórico, ao se propor em desenvolver o conhecimento da sequência natural das notas musicais, porém com uma abordagem lúdica e espontânea. Esta abordagem fez com que o estudo de conteúdos teóricos não se tornasse enfadonho. Além de servir de motivo de descontração da tensão muito comum nas primeiras aulas, quando os alunos geralmente ainda não se conhecem. $O$ fato de se expor e o de ver os outros alunos também se expondo na participação da atividade se complementaram em criar um ambiente solidário e descontraído na sala de aula de música.

A segunda atividade traz consigo outro conteúdo, além da criatividade, bastante discutido nos métodos ativos em educação musical que é o ritmo. $O$ fato de executar, imitar e criar motivos e células rítmicas em grupo trouxe a primeira experiência de aprendizado coletivo, foi possível observar alunos que ao se perderem na execução observavam os alunos a sua volta (que buscavam se expor para ajudar o colega visualmente) para se corrigir, a interação também ocorreu diversas vezes em que um aluno se solidarizava em ajudar o colega com dificuldades mostrando the os movimentos de execução de forma mais lenta.

Com uma abordagem espontânea, no momento de criação em que cada aluno criaria uma frase a ser imitada pelos colegas de maneira ininterrupta até o fim da participação de todos, essa 
atividade não só estimulou a criatividade ao criar frases, mas estimulou a criação espontânea uma vez que não era dado tempo de pausa na atividade para que cada um criasse sua frase.

A terceira atividade, musicalmente mais complexa, apresentou aos alunos uma estrutura menos fragmentada da música, estimulando uma compreensão referente à forma musical. Da mesma maneira que na segunda atividade, os alunos buscavam executar frases musicais, porém com o objetivo de completar uma estrutura maior. O prévio conhecimento desenvolvido na primeira atividade foi de fundamental importância para realização da terceira, ainda pudemos observar a interatividade e solidariedade entre os alunos em relação a este conteúdo.

Nas três atividades trabalhadas que funcionaram como uma sequencia de procedimentos, a fluência musical esteve presente e foi estimulada em todos os momentos, isso foi possível através de uma abordagem lúdica e espontânea. As atividades de apoio foram usadas para fundamentar a execução das atividades musicais diretas conforme o modelo pedagógico de Swanwick (2003).

\section{A FLUÊNCIA MUSICAL NAS ATIVIDADES DESENVOLVIDAS}

Para obter fluência musical desde o início do processo de aprendizado, observamos que as habilidades técnicas, os conhecimentos relacionados a teoria musical e história da música se desenvolveram em um ritmo menos acelerado. Esses conhecimentos não foram ignorados durante todo o processo, mas cumpriram um papel de apoio às atividades principais, ou seja, aquelas relacionadas diretamente à execução musical, conforme indicado por Swanwick (2003). Da mesma forma, as habilidades técnicas relacionadas ao manuseio do instrumento musical apoiaram e complementaram a execução do mesmo.

Ainda no intuito de preservar a fluência musical, delineamos uma ordem de prioridades das atividades primárias ficando em primeiro lugar execução do instrumento musical, em segundo a criação musical, e em terceiro atividades de apreciação musical. As atividades secundárias, de cunho teórico e técnico, foram realizadas em pequenos períodos de tempo durante as aulas conforme se observou a necessidade.

Seguindo esta ordem de prioridades observamos que inicialmente os alunos desenvolveram fluência musical com um nível técnico e de conhecimento teórico razo, considerando que para alunos iniciantes seria uma exigência exacerbada de concentração manter a correta postura e equilibrio corporal, a postura de manuseio do instrumento, o controle da respiração e da coluna de ar, a correta embocadura, a leitura do código musical (partituras), e por fim a execução do instrumento simultaneamente.

Para tornar esse inicio de aprendizado mais fluente, consideramos necessário eliminar as exigências de concentração que não estavam relacionadas a execução instrumental como, por exemplo, o manuseio do instrumento (montagem e desmontagem além de higienização). Desta forma, nas aulas iniciais os alunos aprenderam a produzir o som dos instrumentos utilizando apenas as 
boquilhas e bocais ao invés de terem de manusear os intrumentos inteiros que em alguns casos são grandes e pesados. Outra exigência a ser eliminada foi a da leitrua do código musical que foi substituída inicialmente por uma notação não formal dotada de sinais simples e já conhecidos, como flechas, números, circulos, ondas e etc.

A correta embocadura foi parcialmente cobrada nas aulas iniciais, mas antes foi necessário deixar que os alunos explorassem as boquilhas e bocais com explicações simples e rápidas, do contrário teríamos dotado a aula de muitas explicações e pouca execução. Nesse primeiro momento de aprendizado que podem compreender entre quatro e oito aulas, considerando duas aulas semanais, os alunos realizaram uma execução ao máximo livre de explicalções e cobranças, para não correr o risco de ser um início de exacerbada dificuldade e experiência frustrante para os alunos.

O simples fato de produzir som através das boquilhas e bocais foi de grande estímulo inicial ao alunos, ainda que não houve afinação satisfatória, gradualmente os alunos aprenderam a controlar o volume de som, respiração, posição da embocadura, coluna de ar e afinação das notas.

Dessa forma foi proporcionado aos alunos um tempo de adaptação à atividade central na execução de seus instrumentos que é soprar e produzir som fluentemente, quando isso se tornou uma execução fluente para os alunos, eles puderam se concentrar em mais uma atividade simultaneamente como segurar e manter corretamente posicionado o instrumento musical inteiro nas mãos, e aos poucos foram adquirindo maior habilidade de manuseio do instrumento, e maior êxito em todas as atividades correlacionadas ao fazer musical.

Os resultados descritos neste trabalho foram possíveis ao observar que para Swanwick (2003) as habilidades técnicas, conhecimento teórico e hisórico devem se desenvolver gradualmente enquanto a ênfase deve estar na fluência musical, portanto estimular a criatividade dos alunos desde o início também deve ser uma prioridade no processo de aprendizado.

Uma vez que as atividades musicais diretas são apoiadas pelas atividades musicais não diretas que não devem ter ênfase no inicio, é preciso ter consciência do nível de desenvolvimento musical geral de cada aluno, sendo que sua fluência musical estará acondicionada às habilidades que pouco a pouco for desenvolvendo. Um aluno que estude há seis meses, terá maior fluência musical do que um aluno que estuda há um mês apenas, porém a sua fluência, musicalidade e criatividade devem ser estimuladas a cada fase sem extrapolar o nível de seus conhecimentos e habilidades técnicas.

\section{RESULTADOS OBTIDOS}

As atividades foram sistematizadas segundo o modelo pedagógico de Swanwick (2003), como já descrito a primeira atividade tratando de conteúdo teórico que viria apoiar a terceira atividade, a segunda atividade de execução e criação coletiva e a terceira atividade com o objetivo central do fazer musical dentro de uma estrutura mais complexa quanto à forma musical. 
Foi possível perceber que as abordagens lúdicas e dinâmicas nas atividades de estímulo a criatividade criaram um ambiente descontraído e desviaram gradualmente a atenção de alguns alunos de sua timidez, sendo que uma resposta imediata a qualquer estímulo musical se tornou cada vez mais comum entre os alunos. Isso aconteceu principalmente quando o educador conseguiu envolver os alunos de maior resistência e timidez com a resolução da problemática apresentada de forma lúdica e dinâmica.

A aplicação da primeira atividade apresentada logo na primeira aula da turma iniciante teve um papel fundamental para desenvolver esse ambiente descontraído, pois esse é um momento em que na maioria dos casos os alunos ainda não se conhecem, e uma vez envolvidos pela "brincadeira" musical apresentaram um comportamento mais espontâneo na sala de aula de música do que em outros casos de aulas iniciais com atividades tradicionais como as de apresentação pessoal, por exemplo.

Em todas as turmas envolvidas na análise para este trabalho, alguns alunos mostraram resistência em se envolverem na atividade, porém essa resistência foi abandonada já na primeira aula em todos os casos, mesmo que alguns alunos ainda apresentavam sinais de timidez nas aulas seguintes. Observamos ainda que os alunos na faixa etária entre oito e onze anos mostraram maior envolvimento, e na maioria dos casos menor timidez. Já entre os alunos com doze anos ou mais, a timidez e a resistência em se envolver na atividade com os outros alunos duraram maior tempo, o que em média foi superado após os primeiros quinze minutos de aula.

Na segunda atividade apresentada, observamos um grande estimulo a criatividade musical do aluno, mesmo que amparado por conhecimentos teóricos e habilidades técnicas rasas, a atividade foi eficaz no que se propõe a estimular a criatividade dos alunos iniciantes. Quanto mais profundos seus conhecimentos teóricos, e melhor desenvolvidas suas habilidades técnicas os alunos se viram em situações cada vez mais ricas em possibilidades de criar, utilizando-se de mais elementos musicais disponíveis em seu conhecimento, sendo que a tarefa de criar foi se tornando cada vez mais fácil. Nas turmas em que a atividade foi realizada através de palmas antes de utilizar os instrumentos musicais a espontaneidade dos alunos foi mais imediata. Também foi possível observar nessas turmas maior quantidade de frases rítmicas criadas pelos próprios alunos, entendendo que a criatividade está acondicionada às habilidades técnicas dos alunos, podemos concluir que é de extrema importância desenvolver a atividade numa situação em que os alunos já dominem totalmente a técnica de manipulação do instrumento para que haja maior vazão a criatividade.

No caso da terceira atividade apresentada, observamos em especial uma aluna que tendo participado de toda a atividade com êxito, ao final da mesma não soube relatar qual era o nome da música cujo tema foi trabalhado durante a atividade. Isso nos leva a observar que suas atenções estavam totalmente voltadas ao fazer musical, ou seja, a aluna se preocupou e ocupou em fazer música, em tocar as notas corretas de maneira correta baseada na espontaneidade, e em seu "instinto" musical. Enfim, depois de tocar a música por várias vezes, a aluna parou e teve de pensar por alguns instantes antes de dizer qual era a música que acabara de tocar no saxofone. 
Na maioria dos outros casos muitos alunos perceberam logo no inicio da atividade qual era o tema que estava sendo executado, porém era muito comum observar alguns alunos cantando, ou tocando o instrumento durante a atividade sem ter consciência de qual música estava tocando, isso pôde ser observado porque a todo o momento o educador perguntava quais alunos já sabiam qual era a música, e mesmo que por algum tempo sem saber qual música era, esses alunos percebiam se cantavam no momento errado, ou ainda quando tocavam a nota errada de maneira espontânea.

Nessa atividade percebemos que a mesma cumpriu seu papel de estimular a espontaneidade do aluno ao tocar seu instrumento musical. Envolveu os alunos em tocar de maneira espontânea, e, concentrados no "fazer musical" e sem preocupações com informações adicionais e não musicais como, por exemplo, o nome da música que estava sendo tocada.

As variações dessa atividade são na realidade uma evolução, disposta em três momentos: Em primeiro lugar o educador e os alunos executam a música vocalmente com repetição de uma única sílaba. Em segundo foi inserida a letra da música usando as notas musicais e todos cantaram completando as frases. Em terceiro lugar o educador cantou a letra inserida à melodia e os alunos responderam tocando no instrumento, executando as notas relacionadas à letra que cantaram anteriormente, e na fase final o educador tocou sua parte em seu instrumento e os alunos também tocaram completando as frases.

O trabalho no primeiro momento da atividade teve ênfase na execução musical, eliminando preocupações com questões teóricas, como por exemplo, as notas que deveriam ser usadas para completar a melodia corretamente, esse conteúdo foi trabalhado no segundo momento da atividade. Neste segundo momento o aluno já executava a melodia fluentemente, foi com a inserção da letra criada que o aluno teve de recorrer aos conhecimentos desenvolvidos previamente (na primeira atividade apresentada neste artigo) para resolver a questão de qual nota deveria usar em cada situação apresentada pela letra cantada, o aluno fazia uso da resolução da questão para executar a próxima frase.

A prontidão com que os alunos respondiam as situações-problema propostas na sala de aula também pôde ser observada em outras situações, como no dia 04 de abril de 2011 durante audição pedagógica. Nesta ocasião enquanto o educador explicava ao público como a terceira atividade havia sido trabalhada em sala de aula, após cantar a primeira frase da música, um dos alunos que estavam posicionados para se apresentarem tocou no saxofone completando a frase que havia sido cantada, e da maneira mais improvisada possível a apresentação aconteceu naquele mesmo momento quando os outros alunos também passaram a tocar completando as frases. 


\section{CONSIDERAÇÕES FINAIS}

A reflexão deste trabalho traz a discussão sobre a necessidade de uma abordagem coerente com o referencial teórico baseado em Swanwick (2003), Serafine (1988) e Sloboda (1997) além de contribuir para uma atuação pedagógica do educador musical contextualizada com as novas propostas metodológicas em educação musical apresentadas por Fonterrada (2008).

As atividades foram elaboradas após cinco anos de trabalho no Projeto Guri como forma de aliar o modelo TECLA de Keith Swanwick a prática pedagógica na sala de aula. Estas atividades continuaram sendo desenvolvidas após 2011 em diferentes polos do Projeto Guri no estado de São Paulo, sobretudo nas regionais de Presidente Prudente, Sorocaba e Indaiatuba.

Apesar das particularidades de cada polo e das turmas trabalhadas é possível sistematizar as atividades de forma que possam ser adaptadas as suas realidades.

Os resultados obtidos indicam a possibilidade de que os alunos levem da música para outras áreas uma atitude prática na resolução de situações-problema.

Neste contexto o mais importante é ter em si a possibilidade e a opção de resolver questões intrínsecas à vida (seja uma questão musical ou não) de maneira prática, rápida e eficiente como ocorreu nas atividades da sala de aula. 


\section{REFERÊNCIAS}

1. Associação Amigos do Projeto Guri. Quem somos. Disponível em: $<$ http://projetoguri.com.br/Site3/index.php?option=com_content\&view=category\&layout=blog\&id $=48 \&$ Itemid=86>. Acesso em: 20 Jul. 2012 .

2. BARBOSA, Joel. Da Capo: Método elementar para o ensino coletivo e/ou individual de instrumentos de banda. Jundiaí: Keyboard Editora Musical Itda, 2004. instrumentos de banda. Jundiaí: Keyboard Editora Musical Itda, 2004.

4. DEMO, Pedro. A educação pelo avesso: assistência como direito e como problema. São Paulo, Cortez Editora, 2000.

5. FONTERRADA, Marisa T. O. De tramas e fios: um ensaio sobre música e educação. 2.ed. São Paulo: Editora UNESP; Rio de Janeiro: FUNARTE, 2008.

6. SERAFINE, Mary Louise. Music as Cognition: The Development of Thought in Sound. New York: Columbia University Press, 1988.

7. SLOBODA, John A. A mente musical: a psicologia cognitiva da música. Tradução de Beatriz Ilari e Rodolfo Ilari. Londrina: Eduel, 2008.

8. SWANWICK, Keith. Ensinando música musicalmente. Tradução de Alda Oliveira e Cristina Tourinho. São Paulo: Moderna, 2003.

\section{Fernando Vieira da Cruz:}

Licenciado em Música pela UNIMES, Especialista em Docência no Ensino Superior pela FACON e Mestrando em música pela UNICAMP. Atuou como Educador Musical de 2006 a 2014 no Projeto Guri, e atualmente é Supervisor Educacional do Projeto Guri, desde 2015. 


\section{Dayana Aparecida Marques de Oliveira Cruz:}

Licenciada, Mestra e Doutora em Geografia pela Universidade Estadual Paulista - FCT/UNESP, campus de Presidente Prudente - SP. Professora substituta do departamento de geografia da Unesp, campos experimental de Ourinhos/SP.

\section{Como citar este documento:}

CRUZ, Fernando Vieira da; OLIVEIRA CRUZ, Dayana Aparecida Marques de. REFLEXÕES DA PRÁTICA PEDAGÓGICA VOLTADA A CRIAÇÃO MUSICAL. Reflexão e Ação, Santa Cruz do Sul, v. 26, n. 2, ago. 2018. ISSN 1982-9949. Disponível em: <https://online.unisc.br/seer/index.php/reflex/article/view/4852>. Acesso em: __ doi: http://dx.doi.org/10.17058/rea.v26i2.4852. 